\title{
MIDAZOLAM COMPARED WITH THIOPENTONE AS A HYPNOTIC COMPONENT IN BALANCED ANAESTHESIA: A RANDOMIZED, DOUBLE-BLIND STUDY
}

\section{J.G. Reves, Ronald Vinik, A.M. Hirschfield, Clifford Holcomb, and Sandra Strong}

Midazolam is a 1,4-benzodiazepine derivative (Figure 1) synthesized by Walser and Fryer in 1975. Earlier studies with midazolam have demonstrated its efficacy for induction of anaesthesia ${ }^{1-4}$ and for intravenous premedication. ${ }^{1}$ Midazolam is superior to diazepam for induction of anaesthesia because it causes less burning on injection, is quicker in onset, and there is less individual variation in response to a given dosage. ${ }^{2}$ Midazolam is also short acting with a relatively brief half-life. ${ }^{3}$ Most of the advantages of midazolam over diazepam are a result of its greater water solubility.

The present investigation compares midazolam with thiopentone for use as the hypnotic drug in a balanced anaesthesia regimen. Midazolam compares favourably with and has some advantages over thiopentone.

\section{Methods}

Fifty patients participated in a double-blind comparison of midazolam and thiopentone in a protocol for balanced anaesthesia. The patients were all in ASA physical status I or II and were scheduled for operations under 90 minutes in length. Informed consent was obtained. Table I contains demographic data of the patients divided into the two anaesthetic subgroups, thiopentone and midazolam. Table II lists the various operations.

All patients were premedicated with morphine $0.1 \mathrm{mg} \cdot \mathrm{kg}$ and atropine $0.006 \mathrm{mg} \cdot \mathrm{kg}$. A plastic intravenous cannula was placed in a superficial vein on the dorsum of the hand or forearm for drug and fluid administration. Midazolam was

Address for Reprints: Dr. J.G. Reves, Department of Anesthesiology, University of Alabama Medical Center, University Station, Birmingham, Alabama 35294.

J.G. Reves, M.D., Ronald Vinik, M.D., A.M. Hirschfield, M.D., Clifford Holcomb, M.D., and Sandra Strong, G.R.T. Department of Anaesthesiology, University of Alabama in Birmingham Medical Center.

Supported by a Grant from Hoffmann/LaRoche Incorporated.

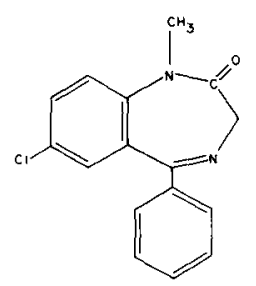

Diazepam (Volium)

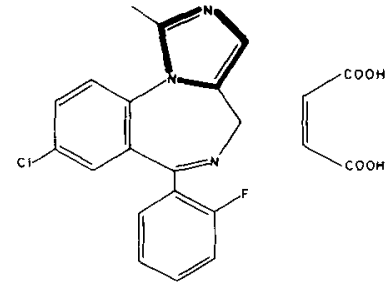

Midozolom Maleate
Figure 1. Chemical structure of midazolam: 8chloro- 6- (2-fluorophenyl)-1-methyl- $4 \mathrm{H}$ - imidazo (-) $[1,5-\mathrm{a}][1,4]$ benzodiazepine maleate (right) and diazepam: 7- chlorolomethyl- 5- phenyl- 3H- 1,4benzodiazepine- 2 (1H)-one (left). Note the imidazole ring (bold line) substitution in midazolam which contributes to increased aqueous solubility.

prepared as $2.5 \mathrm{mg}$ base equivalent per $\mathrm{ml}^{*}$ and thiopentone as $37.5 \mathrm{mg} \cdot \mathrm{ml}$, these ensuring equipotent volumes for induction of anaesthesia with $0.2 \mathrm{mg} \cdot \mathrm{kg}$ midazolam and $3 \mathrm{mg} \cdot \mathrm{kg}$ thiopentone. Both drugs were shrouded in a $15 \mathrm{cc}$ syringe and the appropriate volume was given intravenously for induction over $5-10$ seconds while the patients breathed room air. Maintenance of anaesthesia consisted of nitrous oxide and oxygen $(4: 21 \cdot \mathrm{min})$ and repeated injections of the hypnotic agent (thiopentone or midazolam) with a maximum of three doses, each one third of the original dose. The need for these supplements was based on signs of inadequate anaesthesia, namely tachycardia $\geq 150$ per cent of initial rate, systolic blood pressure (SBP) $\geq 135$ per cent of initial level, diaphoresis or movements. If three additional doses did not meet these criteria of adequate anaesthesia, other adjuvant drugs were given. These were fentanyl, enflurane or halothane at the discretion of the anaesthetist. Succinylcholine $1 \mathrm{mg} \cdot \mathrm{kg}$ was used as an initial bolus for tracheal intubation, and during maintenance a continuous infusion of 0.2 per cent solution was

*Supplied by Hoffmann-La Roche Incorporated, Nutley, New Jersey 07110 . Each $\mathrm{ml}$ contained $2.5 \mathrm{mg}$ base equivalent of midazolam in a solution of tartaric acid $4.0 \mathrm{mg}$, disodium edetate $0.1 \mathrm{mg}$, sodium chloride $7.0 \mathrm{mg}$, benzyl alcohol $0.01 \mathrm{ml}$, and $\mathrm{NaOH} 10$ per cent to adjust $\mathrm{pH}$ to 3.3 . 
TABLE I

Demographic Data of Patients

\begin{tabular}{lccccccc}
\hline \multicolumn{1}{c}{ Group } & $\mathrm{N}$ & Male & Female & Age (yrs) & Wt (kg) & $\begin{array}{c}\text { Duration } \\
\text { anaesthesia (min) }\end{array}$ & $\begin{array}{c}\% \text { Hx previous } \\
\text { anaesthesia }\end{array}$ \\
\hline Midazolam & 24 & 1 & 22 & $34 \pm 2.6$ & $66 \pm 3.6$ & $69 \pm 8.2$ & 60.9 \\
Thiopentone & 26 & 1 & 25 & $33 \pm 2.1$ & $64 \pm 2.8$ & $75 \pm 6.9$ & 69.2 \\
\hline
\end{tabular}

No significant difference in any category.

TABLE II

List of OpERATIONS FOR EACH Group

\begin{tabular}{lrlr}
\hline \hline \multicolumn{2}{l}{ Midazolam (pts) } & \multicolumn{2}{c}{ Thiopent (pts) } \\
\hline LTL & 14 & LTL & 15 \\
TVH & 5 & TVH & 7 \\
TAH & 1 & TAH & 1 \\
Rad & 2 & Rad & 1 \\
End & 1 & End & 1 \\
DL & 1 & Con & 1 \\
\hline
\end{tabular}

Where: $\mathrm{LTL}=$ laparoscopic tubal ligation, $\mathrm{TVH}=$ vaginal hysterectomy, $\mathrm{TAH}=$ abdominal hysterectomy, End $=$ endoscopy, $\mathrm{Rad}=$ vaginal radium insertion, DL = diagnostic laparotomy, Con $=$ cervical conization.

used, monitored with a peripheral nerve stimulator.*

Observations comparing the two groups were arbitrarily divided into three periods: (1) induction, (2) maintenance, and (3) recovery. The ease of induction was graded by the anaesthetist on a three-point scale: $1=$ smooth, $2=$ acceptable, 3 $=$ unacceptable. The times (in seconds) to lose eyelid reflex and to fail to respond to oral command were measured as indices of induction time. Pain on injection was graded by the anaesthesiologist on a 3-point scale of $1=$ none, $2=$ little and 3 = severe. Blood pressure (Riva Rocci) and electrocardiogram (standard lead limb II EKG) were monitored at fixed intervals of 1 to 2 minutes during the first 20 minutes and at $\leq 5$ minute intervals thereafter.

Maintenance of anaesthesia was also graded by the anaesthetist on a 4-point scale of $0=$ excellent, $1=$ good, 2 = satisfactory and $3=$ unsatisfactory. The duration of anaesthesia, number of supplemental injections of hypnotic agents, and the requirement for adjuvant anaesthetic drugs were recorded. To compare muscle relaxant requirements, the dosage of succinylcholine for each patient was computed on a kilogram body weight

*Professional Instruments Co., Houston, Texas. basis over duration of anaesthesia $(\mu \mathrm{gm} \cdot \mathrm{kg}$. $\min$.

Postoperative analysis began with measuring emergence time which was defined in two ways: (1) response to spoken word and (2) full orientation as to person, place and time. During emergence the following particular signs or symptoms were noted if present by the same trained observer: nausea, vomiting, delirium and dreaming. The patients were interviewed 24 hours after anaesthesia by the same observer and asked if they recalled pain on induction and if so were asked to quantitate the pain on a 3-point scale of $1=$ mild, $2=$ moderate and $3=$ severe. Subjects also were asked whether they remembered waking in the operating room or in the recovery room. Patients who had previous anaesthesia were asked to compare the present experience to their previous anaesthesia as either the same, better or worse.

\section{Results}

Fifty patients entered the study, 26 received thiopentone (Group T) and 24 midazolam (Group $M)$. There was no significant difference between groups in sex, age, weight, duration of anaesthesia, or per cent with a history of previous anaesthesia (Table I). One patient in Group M was excluded from analysis during the maintenance and postoperative periods because the operation was protracted ( 2.5 hours). There were no major anaesthetic nor surgical complications in any of the cases. Blood pressure and heart rate did not decrease significantly with drug administration and increased only in response to surgical stimulation.

Table III contains comparative data of the two groups during induction. There was a significant $(P<0.01)$ difference between groups with regard to mean induction times and the ranges were greater in Group M than Group T. Mean lack of response to oral command was shorter in Group $T$ (36 range $15-80 \mathrm{sec}$ ) than Group $M$ (64 range 
TABLE III

Midazolam and Thiopentone Induction Data

\begin{tabular}{cccccc}
\hline \hline & $\begin{array}{c}\text { Failure to respond } \\
\text { oral command (sec) }\end{array}$ & $\begin{array}{c}\text { Loss eyelid } \\
\text { reflex (sec) }\end{array}$ & $\begin{array}{c}\text { Percent with } \\
\text { induction pain }\end{array}$ & $\begin{array}{c}\text { Objective score } \\
\text { pain on injection } \ddagger\end{array}$ & $\begin{array}{c}\text { Quality of } \\
\text { of induction } \dagger\end{array}$ \\
\hline $\begin{array}{c}\text { Midazolam } \\
\mathrm{m}=24\end{array}$ & $\begin{array}{c}64 \pm 7.9 \\
(25-210)\end{array}$ & $\begin{array}{c}73 \pm 8.9 \\
(30-240)\end{array}$ & 8.3 & $1.08 \pm .06$ & $1.26 \pm .129$ \\
$\begin{array}{c}\text { Thiopentone } \\
\mathrm{m}=26\end{array}$ & $\begin{array}{c}36 \pm 2.9 \\
(15-80)\end{array}$ & $\begin{array}{c}45 \pm 4.7 \\
(25-135)\end{array}$ & 11.5 & $1.12 \pm .06$ & $1.12 \pm .066$ \\
$\mathrm{P}$ & $0.0015^{*}$ & $\mathbf{0 . 0 0 5 9 ^ { * }}$ & $\mathrm{NS}$ & $\mathrm{NS}$ & $\mathrm{NS}$ \\
\hline
\end{tabular}

Data represents mean \pm S.E. with range below in parentheses.

$\mathbf{P}=$ probability value, $\overline{N S}=$ not significantly different.

* = significantly different.

† Scored: $1=$ smooth, $2=$ acceptable, $3=$ unacceptable.

†Scored: $1=$ none, $2=$ mild, $3=$ moderate.

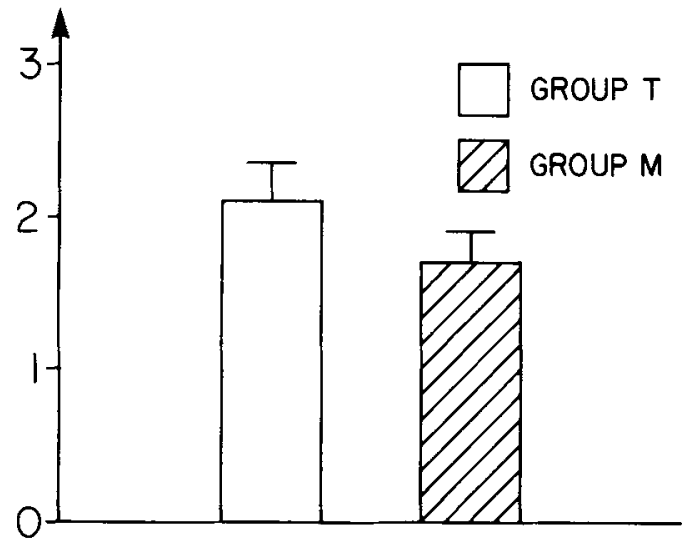

Figure 2. Comparison of quality of maintenance of balanced anesthesia as scored by the anesthetist: $0=$ excellent, 1 = good, 2 = satisfactory, 3 = unsatisfactory. Group $\mathrm{T}$ received thiopentone and Group $\mathrm{M}$ midazolam maleate (see text).

25-210 sec) and mean loss of eyelid reflex was earlier in Group $T$ (45 range $25-135 \mathrm{sec}$ ) than Group M (73 range 30-240 sec). Both groups had similar small percentages of patients who showed signs of pain on induction ( 8 per cent Group $M$ and 12 per cent Group T). The pain appeared mild in all patients. There was no significant difference in scoring the quality of induction between groups $(1.12 \pm 0.066$ Group $T$ and $1.26 \pm 0.129$ Group $\mathrm{M}$ ), but Group $\mathrm{T}$ had a slightly better score.

The duration of anaesthesia was shorter in Group M $(69 \pm 8.2 \mathrm{~min})$, but not significantly different from Group T $(75 \pm 6.9 \mathrm{~min})$. The overall quality of maintenance (Figure 2) was rated better in Group $M(1.7 \pm 0.20)$, but again was not significantly different than Group $\mathrm{T}(2.1 \pm 0.26)$. Supplemental injections of thiopentone were required 63 times to maintain balanced anaesthesia in Group $T$ compared to 45 supplemental injec- tions of midazolam in Group M. Oniy four patients ( 18 per cent) required adjuvant anaesthetic drugs in Group $M$ ( 1 halothane and 3 fentanyl) compared to 12 patients ( 46 per cent) in Group $T$ ( 1 enflurane, 1 halothane, and 10 fentanyl). The mean dosage of succinylcholine $(0.092 \mu \mathrm{gm} \mathrm{kg}$ min) was identical in both groups.

Results of the postoperative observations are in Table IV. There were no significant differences in emergence time and the ranges were similar. Reaction to the spoken word after cessation of nitrous oxide administration occurred in a mean of six minutes (range 1-27) in Group T compared to a mean of eight minutes (range 3-20) in Group M. Patients were fully oriented 34 minutes after termination of nitrous oxide in Group $\mathrm{T}$ (range 6-99 min) compared with 45 minutes Group M (range 6-103). There was no significant difference in the severity of pain remembered during injection of the hypnotic (mean score 1.1 both groups) nor ariy significant difference in the percentage of patients recalling any injection pain ( 27 per cent Group T and 39 per cent Group M). Two patients recalled part of the operation and both were in the thiopentone group. Although not significantly different, 17 per cent of patients in Group $M$ remembered waking up in the operating room whereas 35 per cent in Group $T$ had such recollection. The remaining patients in Group $T$ recalled waking in the recovery room while three patients ( 14 per cent) in Group $M$ had no recall of the recovery room despite having appeared fully oriented. There were significant differences in patients' comparison of anaesthesia with their previous experience. Seventy-one per cent of the patients in the $M$ group found the anaesthesia similar to their previous experience as compared to 31 per cent in the T Group, while 25 per cent of 
group T rated anaesthesia worse than their previous experience versus none with midazolam. The incidence of complications was very low (Table $V)$ and there were no differences in the incidence of nausea, vomiting or venous site irritation. There was a significantly $(P<0.02)$ higher incidence of dreaming in the thiopentone group $(23$ per cent Group T and none in Group M).

\section{Discussion}

Balanced anaesthesia was first described by Lundy in 1926 as the logical choice of a combination of various agents used "in at small enough amount so that it would produce no unsatisfactory effect". 5 Twenty-one years later, Woodbridge further delineated the four essential components of satisfactory balanced anaesthesia as sensory block or block of afferent impulses, motor block or block of efferent impulses, blocking of reflexes, and mental block or production of sleep. 6 There have been many new anaesthetic drugs added to the formulary over the last twenty-one years in an attempt to find more ideal agents to use within the framework of balanced anaesthesia. This report compares a new drug. midazolam, with thiopentone as hypnotic agents in balanced anaesthesia.

Midazolam is a water soluble benzodiazepine. The imidazole substitution at the 1.2 position of the fundamental 1.4 benzodiazepine heterocyclic ring structure (Figure 1) accounts for its solubility in water. Midazolam is an efficacious induction agent in dosages of 0.125 to $0.2 \mathrm{mg} \cdot \mathrm{kg} .{ }^{2.3 .4}$ The $E D_{100}$ for induction of anaesthesia while breathing room air is $0.2 \mathrm{mg} \cdot \mathrm{kg} .{ }^{2}$ Side effects attributed to midazolam during induction of anaesthesia include apnoea, ${ }^{1,2.4}$ mild burning on injection, ${ }^{2.4}$ and slight decreases in systemic blood pressure ${ }^{1,4}$. Advantages of midazolam over diazepam are rapidity of action ${ }^{2}$ less burning on injection ${ }^{2.4}$, and shorter action ${ }^{3}$. Midazolam disappears from plasma more rapidly than diazepam: plasma clearance data for midazolam from five patients given $10 \mathrm{mg}$ intravenously showed a mean half-life during the beta phase of 1.7 hours $^{3.7}$, much shorter than the mean 31.3 hour beta phase plasma disappearance of $10 \mathrm{mg}$ of diazepam measured in another 5 patients. ${ }^{8}$

The purpose of the present investigation was to compare midazolam with thiopentone which has been the "gold standard" of comparison for induction agents, and to compare each drug as the hypnotic component of balanced anaesthesia.

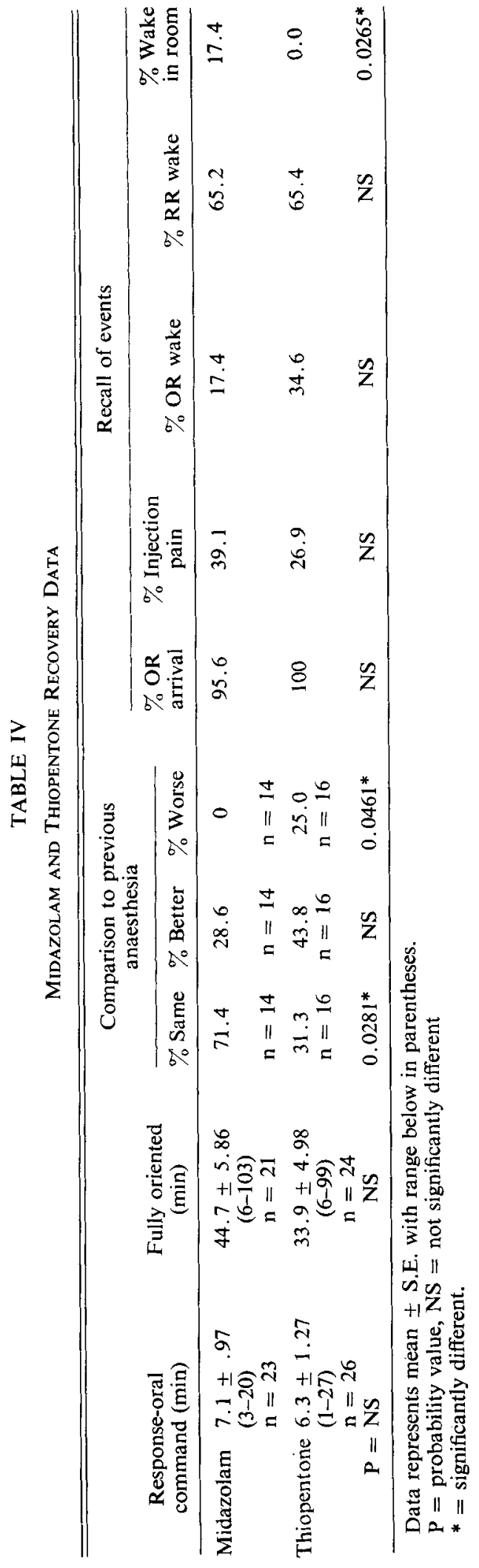


TABLE V

POSTOPERATIVE COMPLiCATIONS

\begin{tabular}{ccccccccc}
\hline & Thrombophlebitis & \multicolumn{2}{c}{ Tissue reaction* } & Dreams & Nausea & Vomiting & Delirium \\
\hline $\begin{array}{c}\text { Midazolam } \\
\mathrm{n}=23\end{array}$ & $\%$ & Day 1 & Day 2 & Day 3 & $\%$ & $\%$ & $\%$ & $\%$ \\
$\begin{array}{c}\text { Thiopentone } \\
\mathrm{n}=26\end{array}$ & 0 & $8.7 \%$ & $21.7 \%$ & $17.4 \%$ & 0 & 0 & 0 & 0 \\
$\mathrm{P}$ & $\mathrm{NS}$ & $\mathrm{NS}$ & $\mathrm{NS}$ & $\mathrm{NS}$ & .02 & $\mathrm{NS}$ & $\mathrm{NS}$ & $\mathrm{NS}$ \\
\hline
\end{tabular}

*Indicates presence of redness, tenderness or combination at site of intravenous, $\mathrm{P}=$ probability.

$\mathrm{NS}=$ not significantly different.

\section{Induction}

Anaesthetists rated thiopentone slightly superior to midazolam in overall quality for induction. The relatively faster onset probably accounts for this superiority since the incidence of pain and discomfort on injection were the same with both drugs. Another advantage of thiopentone was the smaller patient-to-patient variation of dose response reflected by the small standard error of the mean induction times. Although midazolam has less variability of dose response than diazepam, ${ }^{2}$ thiopentone is better than midazolam in this regard. Individual variation in response to diazepam $(0.2-0.8 \mathrm{mg} \cdot \mathrm{kg}$ for induction of anaesthesia) is characteristic of benzodiazepines, ${ }^{9}$ and a major difference between barbiturate and benzodiazepine induction, accounting in part for the continued use of short acting barbiturates for routine anaesthesia induction. ${ }^{10} \mathrm{~A}$ major disadvantage of barbiturate induction is apnoea or respiratory depression which was not analyzed in our study, since all patients were paralyzed and had the trachea intubated. However, previous reports comparing thiopentone with diazepam have shown greater respiratory depression and apnoea with thiopentone. ${ }^{11-13}$ If spontaneous respiration is desired, respiratory depression is, of course, crucial. In this regard, Fragen found that midazolam $(0.15 \mathrm{mg} \cdot \mathrm{kg})$ caused significantly less apnoea than thiopentone $(3 \mathrm{mg} \cdot \mathrm{kg})$ during induction of anaesthesia. ${ }^{4}$

\section{Maintenance}

The maintenance of balanced anaesthesia is difficult to compare. In this study such variables as patient age, size, surgical stimulation and duration of the procedure were all controlled in an attempt to produce relatively homogenous groups for comparison. Statistical comparison of the demographic variables shows that the two groups are similar. Anaesthetists scored midazolam more favorably than thiopentone for maintenance of balanced anaesthesia. This is reflected by the fact that more supplemental injections of thiopentone were required during operation and more adjuvant analgesic drugs were added to thiopentone cases to maintain anaesthesia within the predetermined limits of acceptable depth. The superiority of midazolam over thiopentone in maintaining balanced anaesthesia is similar to the superiority of diazepam over thiopentone reported by Wyant and Studney. ${ }^{13}$ In a study of 200 patients undergoing gynaecological operations randomized to thiopentone or various diazepam doses, those investigators determined that all patients given thiopentone $(3 \mathrm{mg} \cdot \mathrm{kg})$ required greater halothane supplementation than patients induced with diazepam $(0.45 \mathrm{mg} \cdot \mathrm{kg})^{13}$. Although it is generally considered that benzodiazepines are not analgesics, ${ }^{10.14 .15}$ it appears from our data that when used with morphine premedication and nitrous oxide maintenance fewer analgesic drugs are required to maintain anaesthesia with midazolam than with thiopentone. The almost identical requirements for succinylcholine with both drugs suggest that there is little clinically discernible effect of midazolam on muscle relaxation. Benzodiazepines as a class of drugs have well described muscle relaxant properties ${ }^{10,16}$ that are primarily central (supraspinal) rather than peripheral (myoneural) in action. ${ }^{17}$ An early report that diazepam potentiates the myoneural blocking effects of gallamine and antagonizes the effects of succinylcholine ${ }^{18}$ failed to be substantiated in a critical laboratory and clinical study by Dretchen, who demonstrated that clinical doses of diazepam did not potentiate muscle relaxants ${ }^{19}$. Our findings showing no apparent succinylcholine interaction with midazolam are consistent with the findings of Dretchen. 


\section{Recovery}

Emergence from anaesthesia was similar with thiopentone and midazolam. Most previous comparative studies of thiopentone and diazepam have shown that emergence or awakening time is more prolonged with diazepam. ${ }^{9,13,20}$ The relatively short recovery time with midazolam ( 8 minutes to react to spoken word and 45 minutes to become fully oriented) is probably a function of rapid distribution of the drug and early metabolism and excretion. ${ }^{17}$ That emergence from thiopentone is slightly faster than from midazolam may be related to the fact that plasma disappearance of the two drugs is different; that of thiopentone being more rapid (46-48 minutes) ${ }^{21}$ than midazolam (102 minutes). ${ }^{3,7}$ Preliminary in vitro studies show that midazolam undergoes biotransformation by the rat liver, ${ }^{22}$ and that in vivo hydroxylation occurs in the dog and in man, yielding three urinary metabolites. ${ }^{7}$ It is not known whether any of the midazolam metabolites are pharmacologically active, as is the case with diazepam metabolism to the active compounds desmethyl diazepam, oxazepam, and 3-hydroxydiazepam. ${ }^{8}$

A pharmacological property of benzodiazepines is amnesia ${ }^{10,23}$ which was reported as an advantage of diazepam over thiopentone in a previous randomized study of 100 patients (50 each group) for hysterectomy. ${ }^{24}$ In that study 30 per cent of patients given diazepam 15 to $30 \mathrm{mg}$ for induction had "retrograde amnesia" compared to 8 per cent of patients induced with thiopentone 200 to $300 \mathrm{mg}$. Postoperatively 96 per cent of the diazepam patients had amnesia for events in the recovery room compared to 70 per cent with thiopentone. Using a memory card scheme, Conner showed that midazolam $5 \mathrm{mg}$ had amnesic properties for events within 32 minutes after injection in 67 per cent of 24 patients. $^{1}$ He concluded that there was no retrograde amnesia. This is consistent with our finding that 96 per cent of patients remembered entering the operating room and 39 per cent remembered injection. The fact that only 17 per cent of midazolam patients remembered waking in the operating room compared to 35 per cent of those who had thiopentone suggests amnesic action. The significant difference $(p<0.03)$ between percentage of thiopentone patients ( 100 per cent) remembering the recovery room compared to midazolam ( 83 per cent) also suggests an amnesic effect, since all patients appeared to be fully alert and oriented before leaving the recovery room.
Postoperative complications were low in both groups and consisted primarily of redness or tenderness at the site of intravenous cannulation. The absence of thrombophlebitis with midazolam is consistent with human induction data ${ }^{9}$ and with laboratory data showing minimal reaction in the saphenous vein and surrounding tissue in the rat given midazolam 0.038 or $0.125 \mathrm{mg} .{ }^{25}$ The low incidence of nausea and vomiting with thiopentone and midazolam is consistent with that reported for diazepam and thiopentone in a similar group of gynaecological patients. ${ }^{13}$ For the most part, recovery was smooth in patients in both groups with only one patient in the thiopentone group being delirious, although six others did relate postoperative dreams. Midazolam patients were remarkably free of postoperative complications and complaints. Differences in postoperative complications are not statistically significant, but this might be due to the small number of patients in the study.

Midazolam compares favourably with thiopentone as a hypnotic for induction and maintenance of balanced anaesthesia. There are some advantages to each drug. Thiopentone is more rapid and specific for induction of anaesthetic and midazolam is superior for maintenance. In addition there is some degree of postoperative amnesia, a quality patients favour and a fact which is reflected by the overall higher preference grades in the midazolam group. We initiated this study to determine differences between thiopentone and midazolam. Our overall impression is of clinical similarities rather than differences. Although midazolam does not dethrone thiopentone it certainly is a useful hypnotic with definite advantages over thiopentone for maintenance of balanced anaesthesia.

\section{SUMMARY}

Midazolam is a short-acting water soluble benzodiazepine derivative. It is a hypnotic used for intravenous anaesthesia induction. The present investigation was designed in a prospective double-blind fashion to compare midazolam with thiopentone as hypnotic components in balanced anaesthesia. The study included 50 healthy patients undergoing relatively short surgical procedures. The results revealed that thiopentone is faster in onset than midazolam for induction of anaesthesia, with less variation of dose response. However, maintenance of anaesthesia was superior with midazolam, requiring fewer sup- 
plemental anaesthetic drugs, having better patient acceptance and providing more amnesia. Postoperative complications were very low with both techniques. Midazolam was surprisingly similar to thiopentone in most parameters including emergence time from anaesthesia. Midazolam is a new drug with potential both for induction of anaesthesia and maintenance of balanced anaesthesia.

\section{RÉSUMÉ}

Le midazolam est un dirivé hydrosoluble de la benzodiazépine à action courte qui peut être employé par la voie veineuse pour l'induction de l'anesthésie. On compare dans la présente étude les effets hypnotiques du midazolam avec ceux du thiopental lors de l'anesthésie générale balancée en utilisant une méthode prospective à double insu. L'étude englobe cinquante patients en bon état subissant des interventions d'une durée relativement courte. Les résultats montrent qu'à l'induction, l'action du thiopental débute plus rapidement que celle du midazolam et que la relation dose-effet est moins variable.

Cependant. pour le maintien de l'anesthésie, le midazolam a été considéré supérieur. Moins d'agents anesthésiques supplémentaires ont été requis, l'acceptance par le patient a été plus grande et l'amnésie supérieure. Avec les deux techniques, les complications ont été très minimes. La comparaison de la plupart des paramètres incluant la durée de la période de réveil démontre la suprenante similarité des deux agents. En conclusion, le midazolam est un nouvel agent qui pourrait s'avérer très utile pour l'induction et ce maintien de l'anesthésie générale balancée.

\section{ACKNOWLEDGEMENTS}

The authors appreciate the co-operation and encouragement from Dr. Charles Flowers and his colleagues in the Department of Obstetrics and Gynecology during this investigation, and the assistance of Miss Marie Justice in the preparation of the manuscript.

\section{REFERENCES}

1. Conner, J.T., Katz, R.L., Pagano, R.R. \& GRAHAM, C.W. RO 21-3981 for intravenous surgical premedication and induction of anesthesia. Anesth. Analg. 57: 1-5 (1978).
2. Reves, J.G., Corssen, G. \& Holcomb, C. Comparison of two benzodiazepines for anesthesia induction: Midazolam and Diazepam. Canad. Anaesth. Soc. J. 3: 211-214(1978).

3. Brown, C.R. . Sarnquist, F.H. \& Pedley, T.A. RO 21-2981: clinical, electrocephalographic and pharmacokinetic study (abstract). Annual Meeting Am. Soc. Anes., p. 241 (1977).

4. Fragen, R.J., Gahl, F. \& Caldwell, N. A water soluble benzodiazepine, Ro 21-3981, for induction of anesthesia. Anesthesiology 49: 41-43 (1978).

5. LundY, J.F. Balanced anesthesia. Minnesota Medicine 9: 399-404 (1926).

6. WOODBRIDGE, P.D. Changing concepts concerning depth of anesthesia. Anesthesiology 18:536-550 (1957).

7. Puglisi, C.V.. Meyer, J.C.. D’Arconte, L., Brooks, M.A. \& DE Silva, J.A.F. Determination of water soluble imidazo-1,-4-benzodiazepines in blood by electron-capture gas-liquid chromatography and in urine by differential pulse polarography. J. Chromatogr. 145: 81-96 (1978).

8. Kaplan, S.A.. Jack, M.L., Alexander, K. \& WeINFELD, R.D. Pharmacokinetic profile of diazepam in man following single intravenous and oral and chronic oral administrations. J. Pharm. Sci. 62: 1789-1796 (1973).

9. Brown, S.S. \& DundeE, J.W. Clinical studies of induction agents $\mathrm{XXV}$ : diazepam. Brit. J. Anaesth. 40: $108-112$ (1968).

10. Dundee, J.W., Haslett, W.H.K. The benzodiazepines, a review of their actions and uses relative to anaesthetic practice. Brit. J. Anaesth. 42: $217-234(1970)$.

11. Fox, G.S., Wynands, J.R. \& Bhambham, M. A clinical comparison of diazepam and thiopentone as induction agents to general anaesthesia. Canad. Anaesth. Soc. J. 15: 281-290 (1968).

12. Hellewele, J. Induction of anaesthesia with diazepam in Diazepam in Anesthesia. Edited by Knight. P.R. and Burgess, C.G., Bristol, England, John Wright and Sons, pp. 47-51 (1968).

13. Wyant, G.M. \& Studney, L.J. A study of diazepam (Valium) for induction of anaesthesia. Canad. Anaesth. Soc. J. 17: 166-171 (1970).

14. Beaulieu, D., Goyette, M. \& Keeri-Szanto. Anaesthetic time/dose curves: VI. Experiences with diazepam. Canad. Anaesth. Soc. J. 14: 326-331 (1967).

15. Dechene, J.P. \& Desrosiers, R. Diazepam in pulmonary surgery. Canad. Anaes. Soc. J. 16: 162-166 (1969).

16. Greenblatt, D.J. \& Shader, R.1. Benzodiazepines in Clinical Practice. New York, Raven Press. pp. 104-106 (1974).

17. Nagai, S.H., TsenG, D.S.C.\& Wang, S.C. Effect of diazepam and other central nervous system depressants on spinal reflexes in cats: a study of site of action. J. Pharmacol. Exp. Ther. 153: 344-351 (1966).

18. Feldman, S.A. \& Crawley, B.E. Preliminary communications - interaction of diazepam with the muscle-relaxant drugs. Br. Med. J. 2; 336-338 (1970).

19. Dretchen, K., Ghoneim, M.M. \& Long, J.P. The interaction of diazepam with myoneural blocking agents. Anesthesiology 34 : 463-468. 
20. Hollis, D.A. Diazepam as an induction agent, II, in Diazepam In Anesthesia. Edited by Knight, P.R. and Burgess, G.G., Bristol. England, John Wright and Sons, pp. 60-65 (1968).

21. Ghoneim, M.M. \& Van Hamme, M.J. Pharmacokinetics of thiopental: the effects of enflurane and nitrous oxide anesthesia and surgery (abstract). Annual Meeting Am. Soc. of Anes. pp. 425-426 (1977).

22. Woo, G.K., Kolis, S.J. \& Schwartz, M.A. In vitro metabolism of an imiadazobenzodiazepine. The Pharmacologist 19: 164 (1977).
23. Greenblatt, D.J. \& Shader, R.I. Benzodiazepines in Clinical Practice. New York, Raven Press, pp. 204-205 (1974).

24. Stovner, J. \& Endresen, R. Intravenous anaesthesia with diazepam: Acta Anesth. Scand. supp. 24, pp. 223-227 (1966).

25. Pagano, R.R., Graham, C.W., Galligan, K.. CONNER, J.T. \& KaTZ, R.L. Histopathology of veins after intravenous lorazepam and RO 21-3981. Canad. Anaesth. Soc. J. 25: 50-52 (1978). 